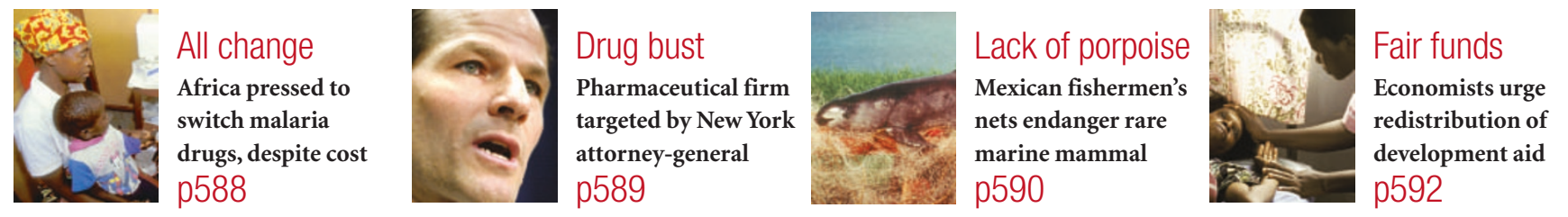

\title{
Gene therapists hopeful as trials resume with childhood disease
}

\section{Erika Check, Minneapolis}

A French gene-therapy trial that cured nine children of a severe disease, but gave two of them cancer, looks set to restart after a 22-month suspension.

The trial involves children who suffer from severe combined immunodeficiency disease (SCID). These children lack innate defences against infections and without treatment they can only survive in isolated environments. One US gene-therapy trial for the disease has also restarted, and others are likely to resume this year.

The suspension of the trials had deeply shaken the gene-therapy field, because SCID was the only disease that had ever been cured by such therapy. Researchers at the annual meeting of the American Society of Gene Therapy in Minneapolis, Minnesota, last week saw the resumption of the SCID trials as a bright spot after a long dark spell for the field.

Specialists say there is still a risk that some children will develop cancer during the trials. But they say the trials should proceed, because the French technique has cured many children who suffer from the devastating illness.

"We're moving forward," says Donald Kohn, past president of the American Society of Gene Therapy and leader of one of the US trials. "No therapy is without risk, and now that we've had time to look back, we realize that this therapy even with the risk may be better than the current treatment," Kohn says.

The children in the French trial suffer from a version of the disease called X-linked SCID. For X-linked SCID patients, the alternative to gene therapy is a bone-marrow transplant. But these transplants are successful in only $70 \%$ of children, unless they have a suitable bone-marrow donor. Out of 18 children treated using gene therapy, 15 appear to have been cured of X-linked SCID.

The French trial, led by Alain Fischer of the Necker Hospital in Paris, was the first to show that infants could be cured through doses of a gene to correct their genetic deficiency. But in September 2002, Fischer announced that he had halted his trial because one of the participants had developed leukaemia. Another

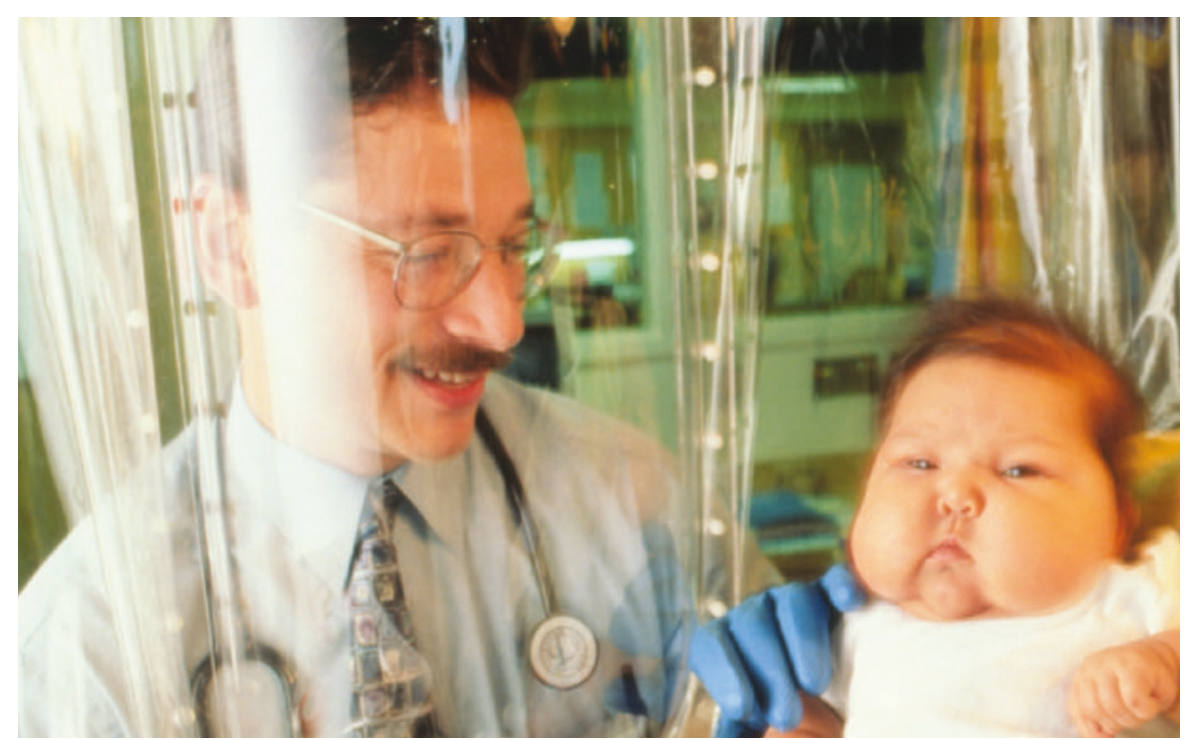

Beyond the veil: Donald Kohn is one of those hoping to cure infants who are unable to fight infections.

child came down with leukaemia a few months later. Both are alive and recovering from their cancers.

Fischer's announcement prompted the US Food and Drug Administration (FDA) to stop three gene-therapy trials in America two in X-linked SCID, and one in another form of the disease called ADA-SCID. But an $\mathrm{X}$-linked SCID study in Britain was allowed to continue, and seven children have now been treated in that study. Claudio Bordignon of the San Raffaele Telethon Institute for Gene Therapy in Milan, Italy, was also allowed to treat patients with ADA-SCID for whom other therapies had failed. Five patients have been treated in that trial, and not one has developed cancer.

The first SCID study to be resumed in the United States is led by Harry Malech and Jennifer Puck of the National Institutes of Health at Bethesda, Maryland. They were cleared to begin their trial in December and treated one child with X-linked SCID in January. So far, his condition is stable, Malech says.

The other two US trials are led by Kohn and by Kenneth Weinberg, both of the Childrens Hospital Los Angeles. Both say that they are consulting with the FDA and hope to resume their trials later this year.
Since 2002, scientists have learned more about why gene therapy caused the X-linked SCID patients to get cancer. Such patients receive a copy of a gene they lack, called the gamma-C gene. This gene allows their immune cells to grow normally. But in the children who get leukaemia, gamma-C seems to switch on a cancer-causing gene called LMO2, which is found in human DNA.

Fischer and other scientists will adjust their treatment plans to minimize risks from this switching effect. For instance, in most cases Fischer will now only treat children older than 6 months, because they might be less vulnerable to cancer than the very young babies who developed cancer in his trial. Fischer will also place an upper limit on the number of corrected cells he injects into the children.

Some researchers take a different tack when balancing the risk of cancer against potential cure. Weinberg is asking the FDA to allow him to resume his X-linked SCID trial without limiting the age of the children enrolled or the dose of cells they receive. But like all other leaders of SCID trials in the United States, Weinberg will monitor each of his patients for signs of cancer for at least a decade after the trial. 